\title{
Mold Nonsinusoidal Oscillation Mode and Its Effect on Slag Infiltration for Lubrication and Initial Shell Growth during Steel Continuous Casting
}

\author{
Xiaobo Yan, Boran Jia, Qiangqiang Wang *, Shengping He and Qian Wang \\ College of Materials Science and Engineering, and Chongqing Key Laboratory of Vanadium-Titanium \\ Metallurgy and Advanced Materials, Chongqing University, Chongqing 400044, China; \\ yanxiaobo@cqu.edu.cn (X.Y.); jiaboran@cqu.edu.cn (B.J.); heshp@cqu.edu.cn (S.H.); q_wang@cqu.edu.cn (Q.W.) \\ * Correspondence: wtfwawj@163.com; Tel.: +86-023-6510-2469
}

Received: 26 February 2019; Accepted: 4 April 2019; Published: 7 April 2019

\begin{abstract}
The effect of nonsinusoidal oscillation at different modification ratios $(\alpha)$ on slag lubrication was investigated during mold oscillation. A validated and reliable multiphase model was employed, which involved flow and solidification of the molten steel and mold slag. The main results revealed that a large amount of liquid slag at the entrance of the mold-strand channel reflowed into the slag pool at the middle of the negative strip period. The phenomenon was more distinct, with an increase in the modification ratio. The modification ratio had no obvious effect on the average thickness of the liquid film at different depths below the meniscus. A modification ratio of 0.5 caused less fluctuation of the transient liquid film. Quantitative prediction of slag consumption indicated that as the modification ratio increased from 0.2 to 0.5 to 0.8 , the average values were $0.278,0.286$, and $0.279 \mathrm{~kg} / \mathrm{m}^{2}$, respectively. Shell solidification and growth near the meniscus mainly occurred when the mold was descending, which not only depended on the heat flux, but also on the liquid slag flow, the pressure driven by slag rim, and the mold oscillation. Optimization of the modification ratio of nonsinusoidal oscillation could be an alternative to delay growth of the initial shell towards the molten steel. A modification ratio of 0.5 had the least robust shell tip at the meniscus, thereby reducing entrapment of inclusions and bubbles by the shell tip.
\end{abstract}

Keywords: numerical simulation; steel; continuous casting; nonsinusoidal oscillation; lubrication; slag consumption; initial shell growth

\section{Introduction}

Mold oscillation technology was pioneered by Junghans [1,2] in the early 1930s and successfully applied to the continuous casting of nonferrous metal, which initiated large scale industrial application. In 1949, Junghans and Rossi [1,2] first implemented an oscillating mold for the continuous casting of steel, with the aim of smooth demolding and friction reduction on the strand surface. In early oscillating molds, the copper plates are always periodically moved downward a certain distance at a velocity equal to the casting speed, and then rapidly returned to the initial position [1]. Consequently, both the absence of gradual varied velocity difference between the mold $\left(V_{\mathrm{m}}\right)$ and strand $\left(V_{\mathrm{c}}\right)$ and the abrupt change in direction of mold movement could cause negative effects on oscillating devices and increase the incidence of breakout. A significant advance was the conversion to sinusoidal oscillation mode [1]. Sinusoidal oscillation eliminated the inherent velocity relationship between the mold and the solidifying shell. This technique performed well in healing tiny cracks on the strand surface during the negative strip period (NSP; $t_{\mathrm{n}}$, the portion of the oscillation cycle where the mold descend faster than the shell) [3-5] and in the demolding process during the positive strip period ( $t_{\mathrm{p}}$, which constitutes the 
remainder of the oscillation cycle). With increasing diversity of continuous casting technology, such as use of high-speed casting and some special steel grades, the adjusting ability of sinusoidal oscillation is, however, limited, because it only depends on the oscillation frequency and amplitude. To satisfy the requirements of further reducing the friction and improving the lubrication conditions exerted on the strand surface, an innovative nonsinusoidal oscillation mode was proposed by Mizukami et al. [6] and Suzuki et al. [7], and a new oscillation parameter-the modification ratio $(\alpha)$-was introduced on the basis of sinusoidal oscillation, as indicated in Figure 1a. $\alpha$ represents the extent of asymmetry of the nonsinusoidal oscillation, which is defined as the time shift of the highest (or lowest) peak from the corresponding sinusoidal peak compared with one-quarter of the total period of the oscillation cycle $[8,9]$.
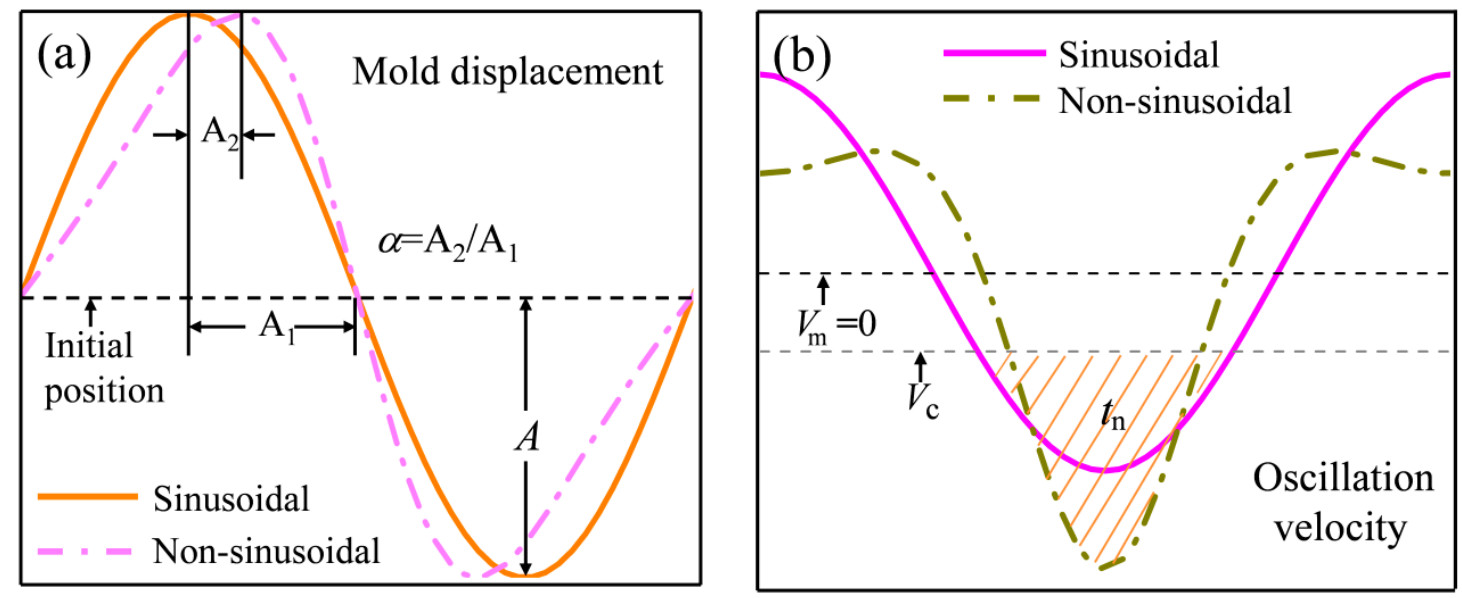

Figure 1. Schematic of sinusoidal and nonsinusoidal oscillation waveform curves: (a) mold displacement and (b) mold oscillation velocity.

Figure $1 \mathrm{~b}$ shows that nonsinusoidal oscillation has a rapid velocity change during the downward oscillation and a shorter $t_{\mathrm{n}}$ and longer $t_{\mathrm{p}}$ than those of sinusoidal oscillation. As previously reported [10-13], oscillation marks on the strand surface become deeper with longer $t_{n}$; hence, the nonsinusoidal mode is favorable in ameliorating the surface quality. The required level of the compressive force imposed on the solidified shell increases with increased relative speed during $t_{\mathrm{n}}$ and, due to the elongation of $t_{\mathrm{p}}$, the decreased relative speed in $t_{\mathrm{p}}$ between the mold and strand can reduce the tensile force exerted on the solidified shell, which may be critical to solder surface cracking and strand demolding [4]. Several industrial trials and laboratory experiments [6,7,9,10,14-19] have been conducted to investigate the influence of nonsinusoidal oscillation mode on the continuous casting process, as summarized in Table 1.

Previous studies indicate that nonsinusoidal oscillation was preferred over the conventional sinusoidal mode in certain aspects, such as enhancement of slag consumption and reduction of the frictional force, yet it was not clear what the mechanisms of slag infiltration were for nonsinusoidal mode. Furthermore, the influence of $\alpha$ on lubrication, which is the most noticeable distinction between the nonsinusoidal and sinusoidal modes, has not been thoroughly studied. In the current study, a validated and reliable multiphase model [20] was applied to investigate the effect of $\alpha$ on lubrication to the shell. The following aspects were studied; liquid slag infiltration at the meniscus, distribution of pressure in the flux channel, liquid film thickness, and transient slag consumption. Growth of the solidified shell at the meniscus with various $\alpha$ was also discussed to provide guidance to select the modification ratio. 
Table 1. Studies of the effect of nonsinusoidal oscillation mode on slag lubrication.

\begin{tabular}{|c|c|c|c|c|}
\hline Method & Main Findings & Authors & Year & Refs \\
\hline Experimental continuous caster & $\begin{array}{l}\text { Nonsinusoidal mode was more effective to } \\
\text { reduce the friction force on the strand surface } \\
\text { by } \sim 60 \% \text { and increased the slag consumption } \\
\text { by } \sim 10 \% \text { compared to the conventional } \\
\text { sinusoidal mode at } 2.0 \mathrm{~m} / \mathrm{min} \text {. }\end{array}$ & Mizukami et al. & 1986 & [6] \\
\hline Industrial trials & $\begin{array}{l}\text { The liquid frictional force decreased by } \sim 40 \% \\
\text { with } 0.4 \text { of } \alpha \text {, and most of the reduction was } \\
\text { attributed to the decrease of relative speed } \\
\text { during the } t_{\mathrm{p}} \text {. }\end{array}$ & Suzuki et al. & 1991 & [10] \\
\hline Industrial trials & $\begin{array}{l}\text { The maximum friction exerting on the initial } \\
\text { shell for the nonsinusoidal mode }(\alpha=0.4) \text { was } \\
\text { reduced by approximately } 62 \% \text { at } \\
2.0-2.2 \mathrm{~m} / \mathrm{min} \text { in comparison with that for } \\
\text { sinusoidal mode. }\end{array}$ & Suzuki et al. & 1992 & {$[7]$} \\
\hline Mold simulator & $\begin{array}{l}\text { Slag consumption improved significantly with } \\
\text { the increased of } \alpha \text { from } 0 \text { to } 0.4 \text {. }\end{array}$ & Tsutsumi et al. & 1998 & [14] \\
\hline Industrial trials & $\begin{array}{l}\text { Nonsinusoidal mode }(\alpha=0.24) \text { resulted in an } \\
\text { increase of slag consumption by } \sim 10 \% \text {. }\end{array}$ & Shin et al. & 2006 & [9] \\
\hline Mathematical model & $\begin{array}{l}\text { With the prolongation of } t_{\mathrm{p}} \text {, the slag } \\
\text { consumption increased, the maximum friction } \\
\text { force on the strand surface decreased } \\
\text { significantly with the increase of } \alpha \text {. }\end{array}$ & Wang et al. & 2010 & [15] \\
\hline Mathematical model & $\begin{array}{l}\text { The liquid slag-film thickness increased from } \\
\text { less than } 100 \mu \mathrm{m} \text { for the sinusoidal case to } \\
200 \mu \mathrm{m} \text { for the nonsinusoidal mode. }\end{array}$ & Lopez et al. & 2012 & [16] \\
\hline Cold model & $\begin{array}{l}\text { Nonsinusoidal oscillation prolonged the } t_{\mathrm{p}} \\
\text { in which the channel was widened, } \\
\text { contributing to more slag consumption and } \\
\text { lowering frictional force. Higher } \alpha \text { increased } \\
\text { the negative pressure and improved the slag } \\
\text { infiltration. }\end{array}$ & Yang et al. & 2014 & $\begin{array}{l}{[17,} \\
18]\end{array}$ \\
\hline Mathematical model & $\begin{array}{l}\text { Increasing } \alpha \text { to } 0.24 \text { slightly increased slag } \\
\text { consumption by } 2.4 \% \text { and the predicted slag } \\
\text { consumption enhanced as the increases of } \alpha \text {. }\end{array}$ & Jonayat and Thomas & 2014 & [19] \\
\hline
\end{tabular}

\section{Solution Methods}

\subsection{Model}

A two-dimensional multiphase model [20] was utilized to investigate the effect of nonsinusoidal oscillation on lubrication to the shell. A schematic of the calculation domain is shown in Figure 2a, which mainly comprises half of a submerged entry nozzle (SEN), an oscillating mold copper plate, and fluid areas including air, molten slag, and steel. Periodic oscillation of the copper plate was realized using the method of dynamic mesh. The mesh of the fluid domain was elaborately refined near the steel-slag interface and adjacent to the copper plate side, in which the minimum cell size was $50 \mu \mathrm{m}$ (Figure 2b). The number of structured grids was approximately 200,000. The time step was increased gradually, and the value of $0.0001 \mathrm{~s}$ was kept after the calculation became stable. The employed mold flux was designed for the continuous casting of low-carbon steel, the basicity and break temperature of which were 0.9 and $1352 \mathrm{~K}\left(1079{ }^{\circ} \mathrm{C}\right)$, respectively. The break temperature, $T_{b}$, was utilized to distinguish the liquid and solid layers. In the temperature range below, $T_{b}$, the slag layer was regarded as solid and, conversely, the slag film was treated as a liquid layer. The viscosity of the mold slag was measured by the rotating cylinder method [21]. Variation of viscosity during the cooling process was as follows 


$$
\eta_{\text {slag }}=\left\{\begin{array}{l}
-0.00152 \times(T-273)+2.14, T>T_{b} \\
-0.11152 \times(T-273)+120.60,1335 \mathrm{~K}<T<T_{b} \\
3.0, T<1335 \mathrm{~K}
\end{array}\right.
$$

where $\eta_{\text {slag }}$ is the viscosity $(\mathrm{kg} /(\mathrm{m} \cdot \mathrm{s}))$ of the slag, $T$ is the temperature $(\mathrm{K})$, and $T_{b}$ is the break temperature $(\mathrm{K})$ of the slag. A comprehensive introduction to the multiphase model, casting parameters, and physical property parameters of the steel and slag used in this study was proposed by Zhang et al. [20].
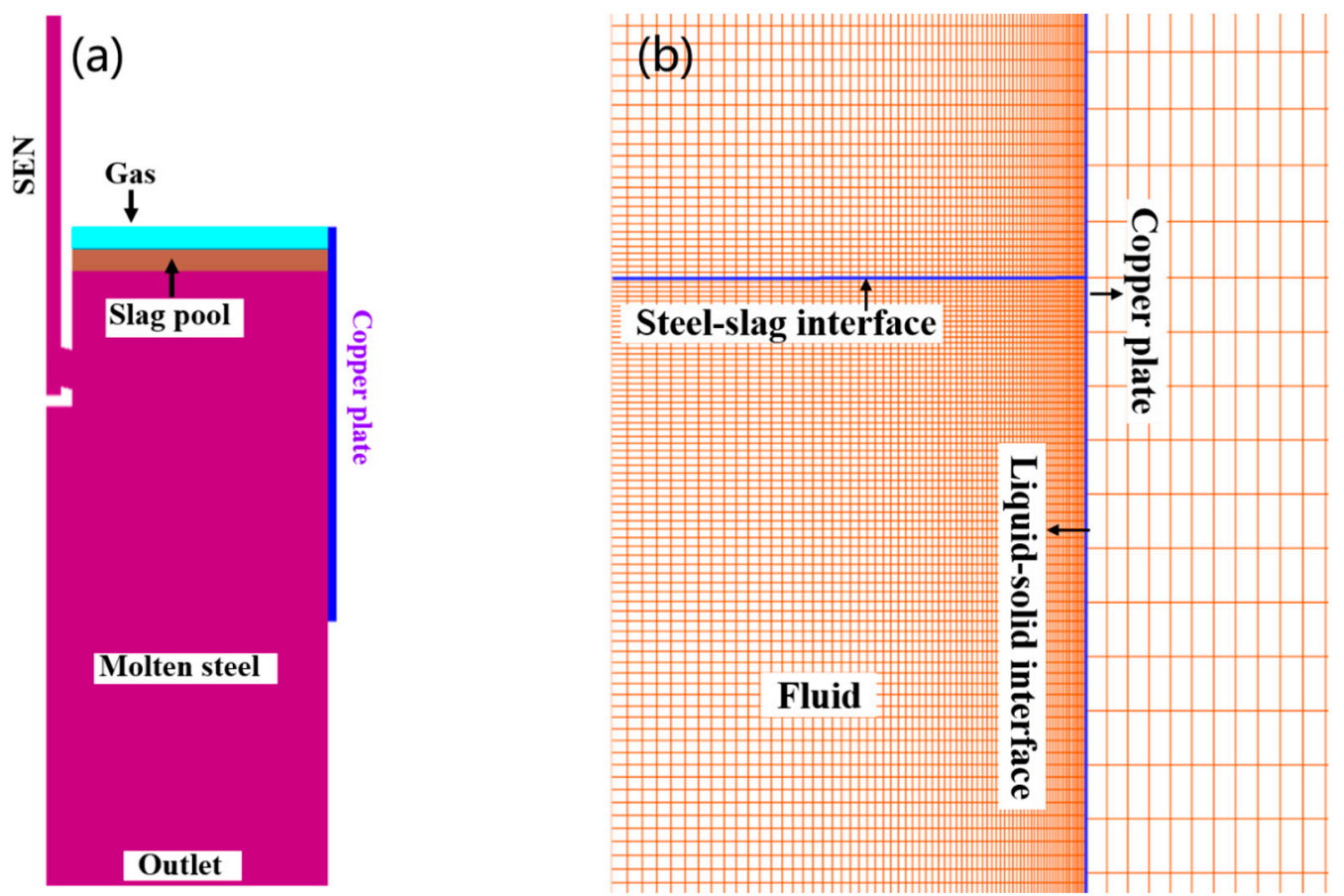

Figure 2. Schematic of (a) mold model and (b) mesh of computation domain.

\subsection{Nonsinusoidal Oscillation Mode}

Three cases of nonsinusoidal oscillation modes with $\alpha$ of $0.2,0.5$, and 0.8 were discussed. The corresponding curves of oscillation velocity were given in Figure 3. The casting speed was $0.9 \mathrm{~m} / \mathrm{min}$, and the mold oscillation amplitude $(A, \mathrm{~mm})$ and frequency $(f, \mathrm{~Hz})$ were $3 \mathrm{~mm}$ and $2 \mathrm{~Hz}$, respectively. The displacement $(S, \mathrm{~m})$ and oscillation velocity $\left(V_{\mathrm{m}}, \mathrm{m} / \mathrm{s}\right)$ of the nonsinusoidal mode were expressed as below.

$$
\begin{gathered}
S=\frac{A}{1000} \sin [2 \pi f t-\alpha \sin (2 \pi f t)], \\
V_{\mathrm{m}}=2 \pi \frac{A}{1000} f[1-\alpha \cos (2 \pi f t)] \cos [2 \pi f t-\alpha \sin (2 \pi f t)] .
\end{gathered}
$$




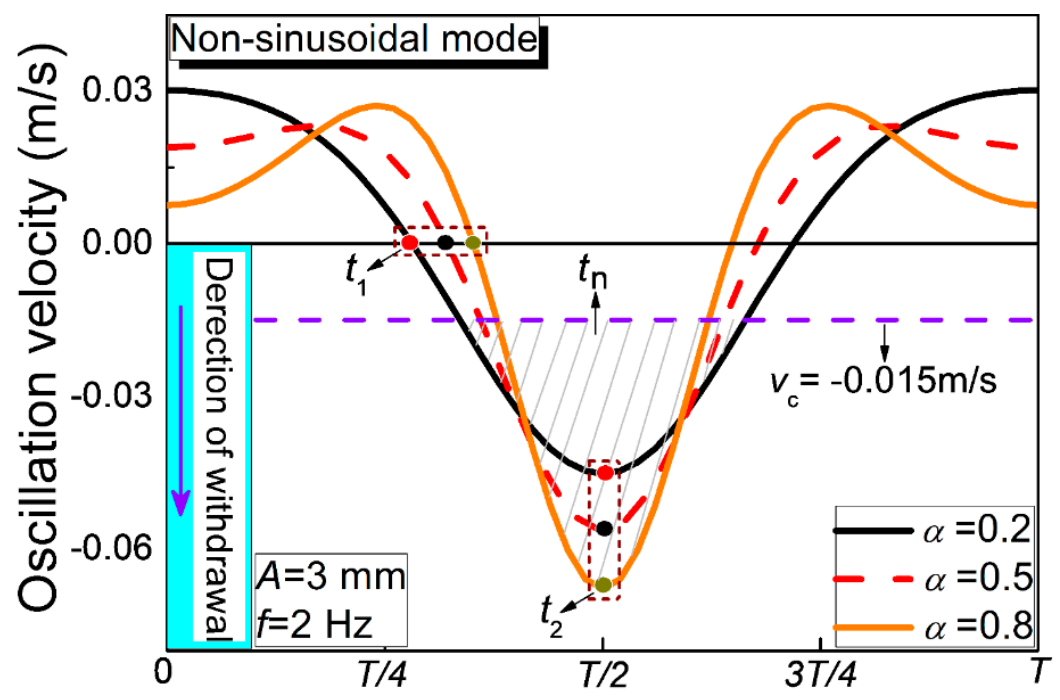

Figure 3. Oscillation velocity of nonsinusoidal mode with different modification ratios.

\section{Results and Discussion}

\subsection{Inflow Behavior of Liquid Slag Near Meniscus}

Two specific moments- $t_{1}$ and $t_{2}$-as plotted in Figure 3 , corresponding to the same oscillation position with different values of $\alpha$, were selected for comparative analysis of the inflow characteristics of liquid slag at the meniscus. At $t_{1}$, the mold ascended to its highest position with zero velocity in $t_{\mathrm{p}}$, while at $t_{2}$, the mold moved back to the initial position with peak downward velocity in the middle of $t_{\mathrm{n}}$. Figure 4 demonstrates the inflow behavior of liquid slag at the entrance of the mold-strand channel, where the liquid slag begins to lubricate the initial solidified shell. To intuitively elucidate the infiltration, the velocity vector of the liquid slag was adopted to indicate its motion. At $t_{1}$, the slag flow was strongly downward into the mouth of mold-strand channel and has an even distribution of velocity for all three cases. Subsequently, as the mold continued to descend and reached the middle of $t_{\mathrm{n}}\left(\right.$ at $\left.t_{2}\right)$ with maximum velocity, a large volume of liquid slag adjacent to the initial shell was squeezed out from the channel and back into the slag pool; the infiltration circumstances of liquid slag predicted in the model was consistent with the reported by Jonayat and Thomas [19]. The flow-back tendency increased with the increase of $\alpha$. The phenomenon is caused by the solid rim descending under the drive of the copper plate, which imposes an oppressive function on the liquid slag and plays the role of a piston occupying the space of the liquid flux [22]. Compared with the sinusoidal oscillation in our previous work [20], the flow-back motion of nonsinusoidal oscillation was more violent than the former during the middle of $t_{\mathrm{n}}$. Additionally, the slag channel became narrower to a certain degree from $t_{1}$ to $t_{2}$ and a broader channel at the meniscus was observed at $\alpha$ of 0.2 than that with higher values of $\alpha$. 
(a)

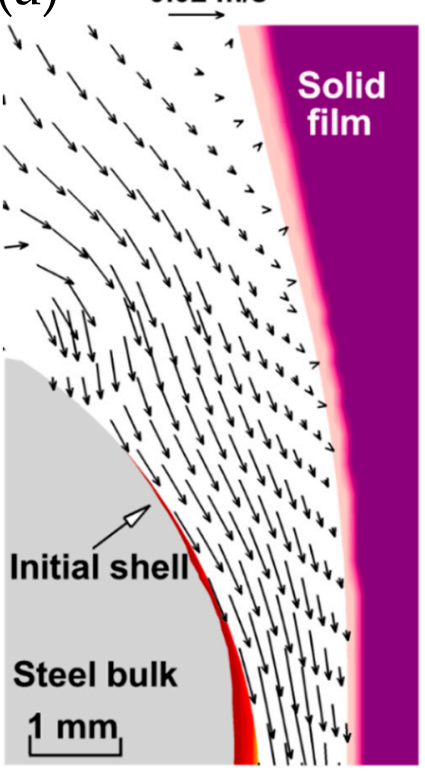

(d)

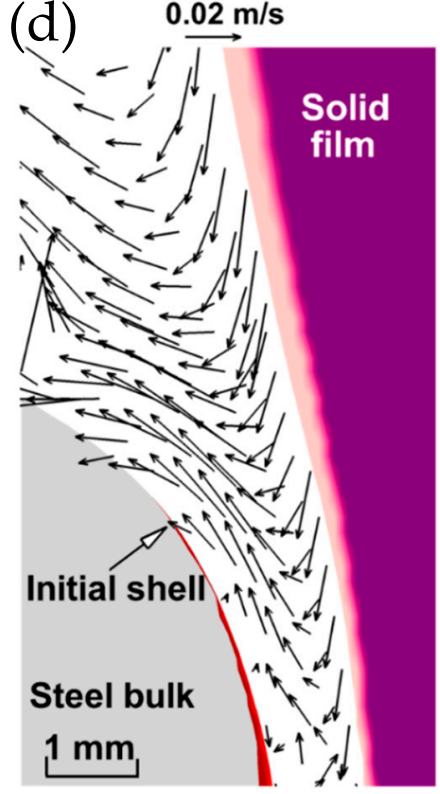

(b)

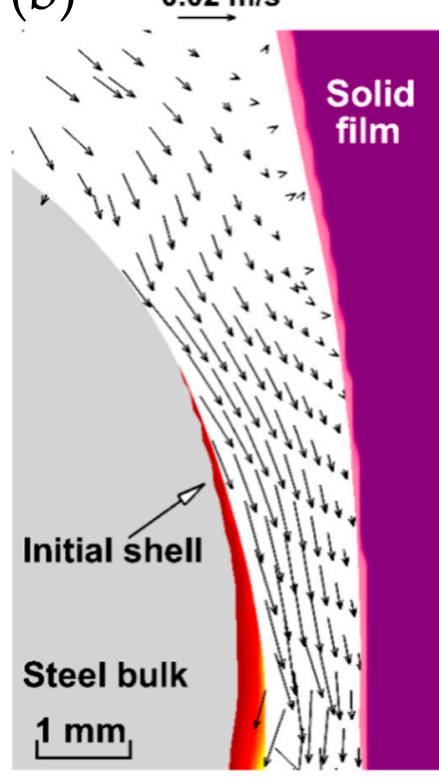

(e)

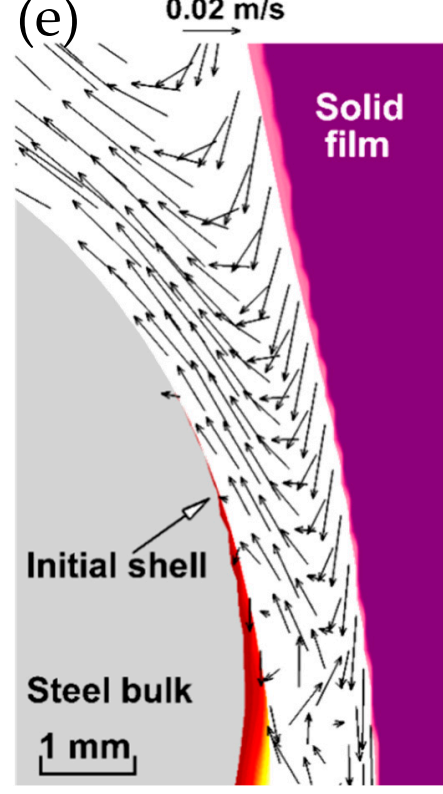

(c)

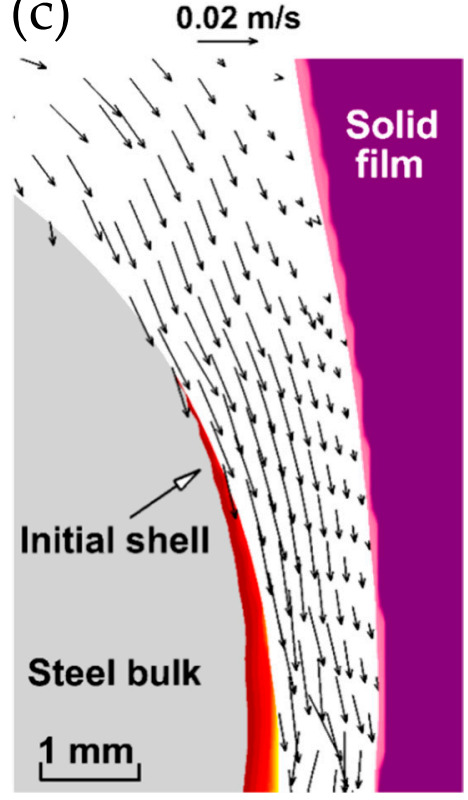

(f)

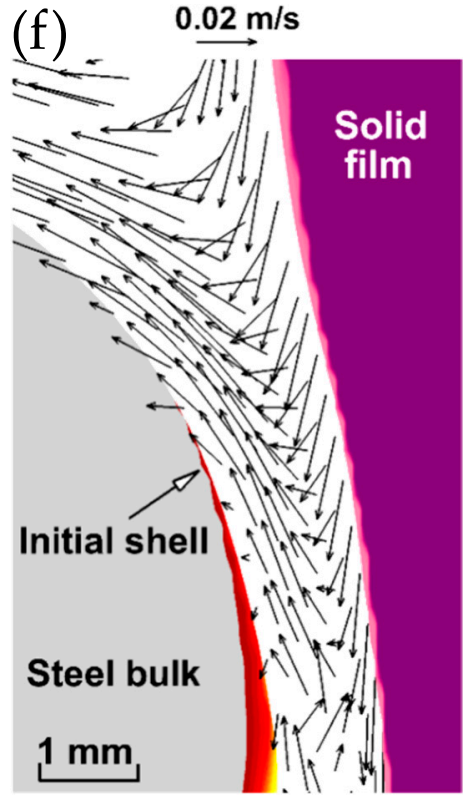

Figure 4. Slag infiltration near the meniscus at different moments for nonsinusoidal oscillation mode: (a) $t_{1}, \alpha=0.2$, (b) $t_{1}, \alpha=0.5$, (c) $t_{1}, \alpha=0.8$, (d) $t_{2}, \alpha=0.2$, (e) $t_{2}, \alpha=0.5$, and (f) $t_{2}, \alpha=0.8$.

Figure 5 shows the corresponding pressure distribution in the slag channel near the meniscus. At $t_{1}$, the downward pressure along the channel gradually increased with increase of $\alpha$; the maximum pressure at the lower part of the channel increased from 1530 to $1650 \mathrm{~Pa}$. At $t_{2}$, the overall pressure in the channel increased, and the region with pressure larger than $1600 \mathrm{~Pa}$ was obviously larger than that at $t_{1}$. The reason was that the copper plate and rim exerted a larger compressive force on the mold-strand channel during downward motion of the mold, which resulted in increased pressure from $t_{1}$ to $t_{2}$. In addition, $\alpha$ did seem to have lesser effect on the pressure at the upper part and further away from the channel entrance during the oscillation cycle. 


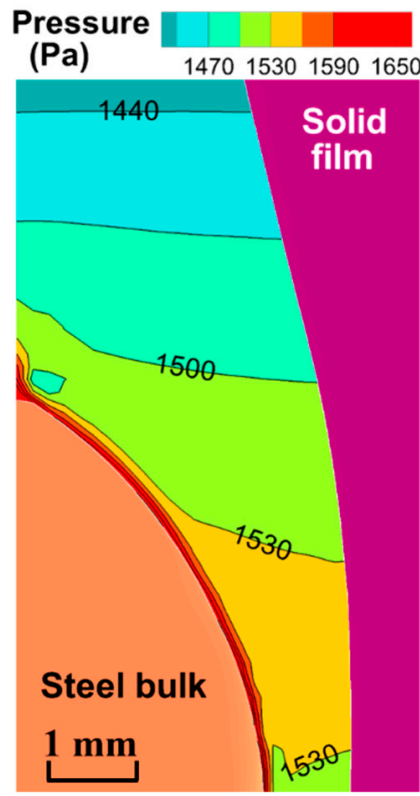

(a)

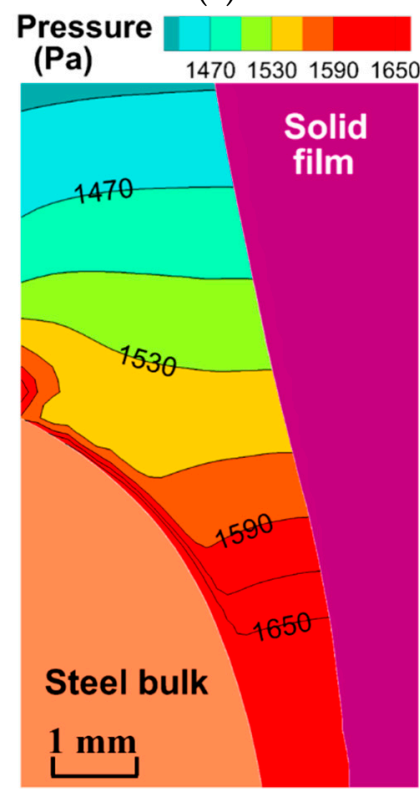

(d)

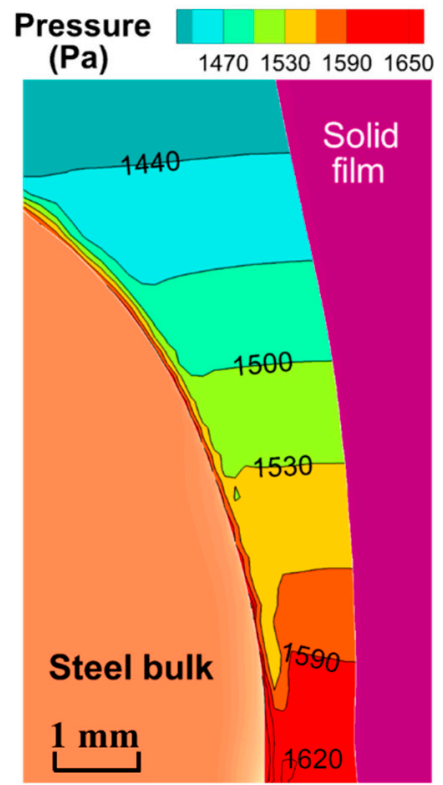

(b)

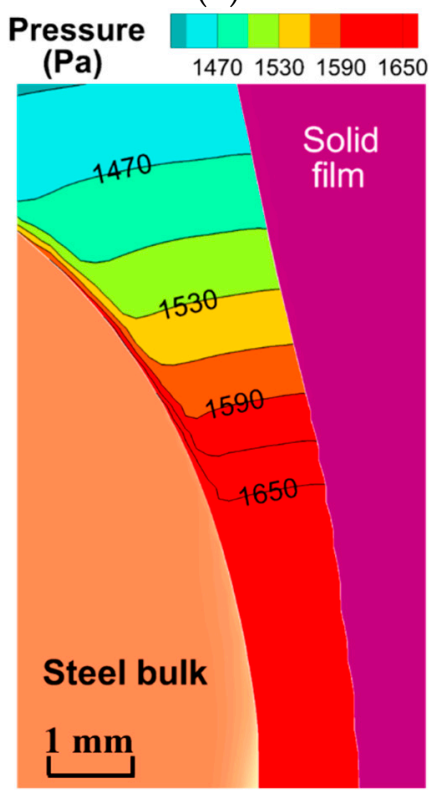

(e)

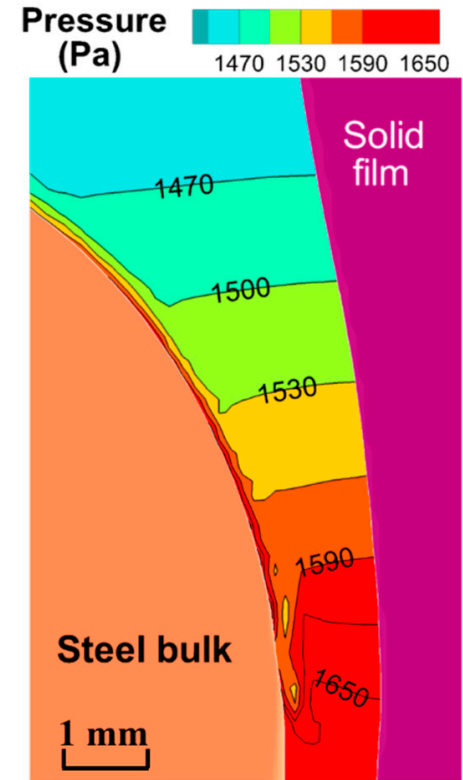

(c)

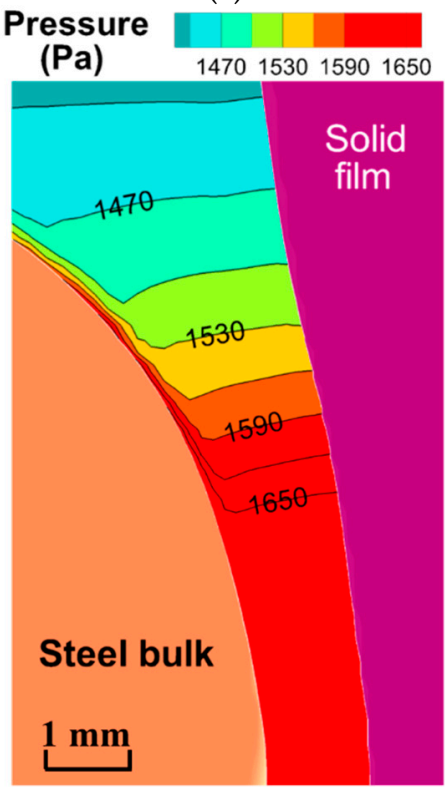

(f)

Figure 5. Distribution of pressure in the slag channel: (a) $t_{1}, \alpha=0.2,(\mathbf{b}) t_{1}, \alpha=0.5$, (c) $t_{1}, \alpha=0.8$, (d) $t_{2}$, $\alpha=0.2,(\mathbf{e}) t_{2}, \alpha=0.5$, and (f) $t_{2}, \alpha=0.8$.

\subsection{Liquid Slag Film Thickness}

Lubrication is closely related to liquid film thickness $\left(d_{1}\right)$. To clarify the effect of nonsinusoidal oscillation, the variations of $d_{1}$ at 100 and $400 \mathrm{~mm}$ below the meniscus were traced, as indicated in Figure 6 . The colored band in the graph represents the NSP. $d_{1}$ changed periodically with the mold oscillation: as $\alpha$ increased from 0.2 to 0.8 , the fluctuation of $d_{1}$ became larger during $t_{\mathrm{n}}$, at locations both 100 and $400 \mathrm{~mm}$ below the meniscus. The calculated average $d_{1}$ showed no differences for the three cases, being 0.35 and $0.13 \mathrm{~mm}$ at the positions of 100 and $400 \mathrm{~mm}$, respectively. To evaluate the stability of the liquid film during mold oscillation, the method of standard deviation was applied. The comparison in Figure 7 revealed that there was a relatively steady variation of transient $d_{1}$ when the modification ratio was 0.5 . 

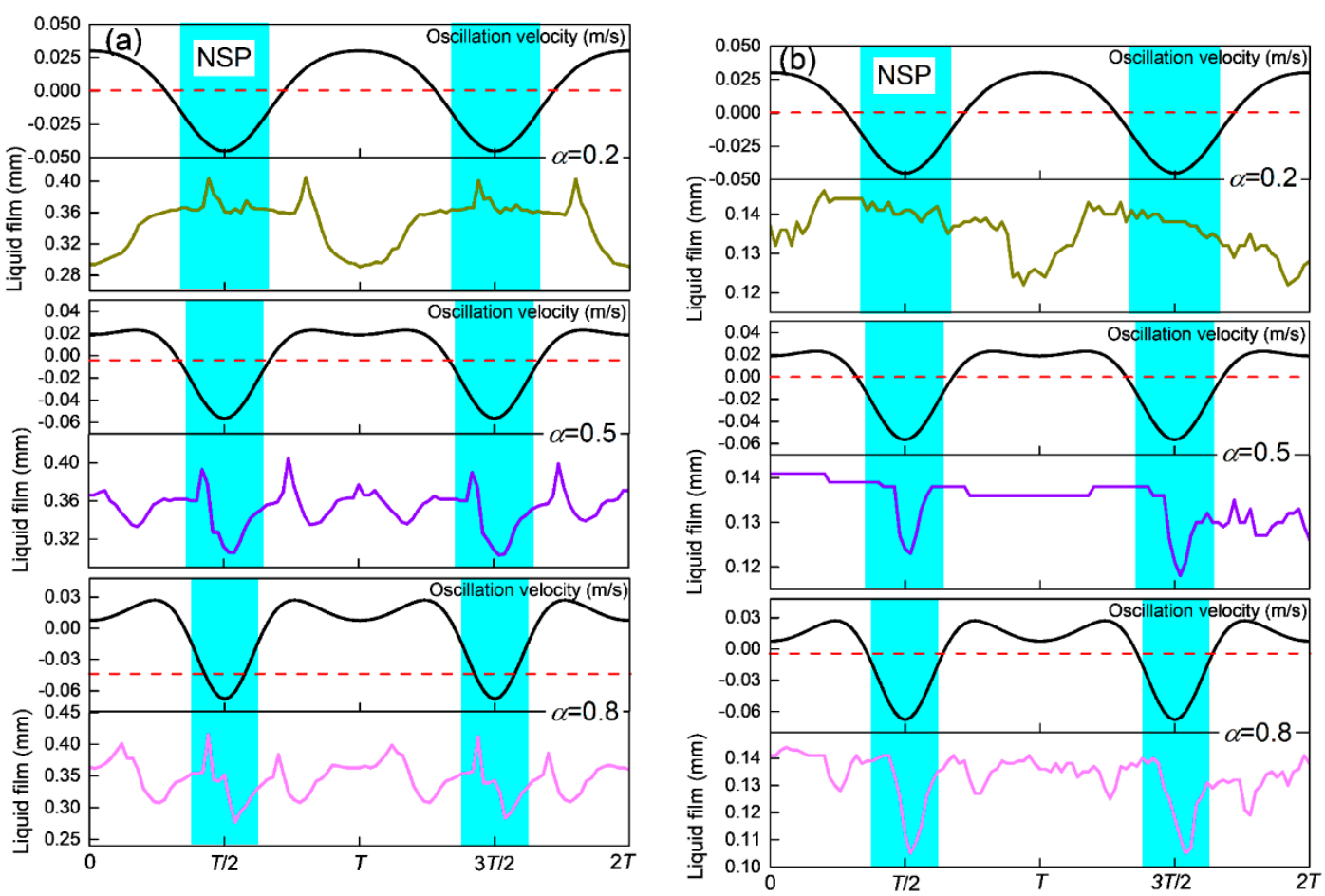

Figure 6. Effect of nonsinusoidal oscillation on the thickness of liquid film at different positions below the meniscus: (a) $100 \mathrm{~mm}$ and (b) $400 \mathrm{~mm}$.

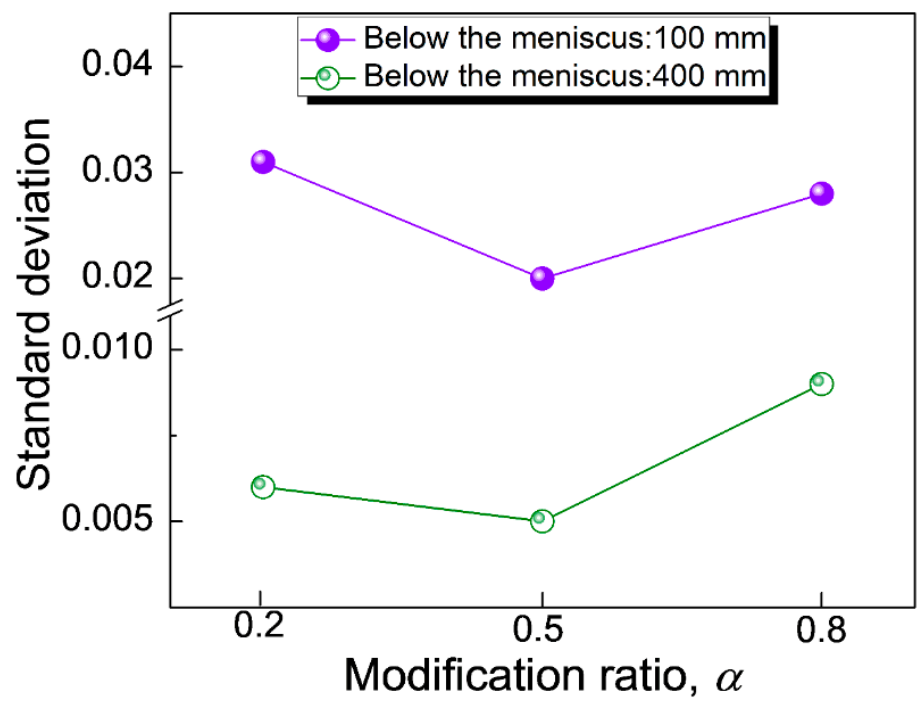

Figure 7. Standard deviation of liquid film thickness with different modification ratios.

\subsection{Slag Consumption}

Slag consumption $\left(Q_{s}\right)$ stems from liquid slag infiltration into the mold-strand gap and its steady consumption with strand withdrawal $[8,9,19,23,24]$. A quantitative method to calculate $Q_{\mathrm{s}}$, which is represented by the slag consumption per unit area of cast slab surface (in $\mathrm{kg} / \mathrm{m}^{2}$ ), is outlined in our previous work [25]. Figure 8 shows the variations of slag consumption with oscillation cycle for different $\alpha$. The evolutions of $Q_{s}$ also presented a periodically analogous fluctuation with the mold reciprocation. At the beginning of $t_{\mathrm{p}}, Q_{\mathrm{s}}$ had less fluctuation; this then persistently decreased from the later part of $t_{\mathrm{p}}$ and reached its lowest value at the middle of $t_{\mathrm{n}}$. As $\alpha$ increased from 0.2 to 0.5 to 0.8 , the minima were $0.15,0.06$, and $0.05 \mathrm{~kg} / \mathrm{m}^{2}$, respectively. $Q_{\mathrm{s}}$ then incessantly increased until late in the cycle of the next $t_{\mathrm{p}}$. The fluctuation of $Q_{\mathrm{s}}$ increased as $\alpha$ increased during 
$t_{\mathrm{n}}$. The maximum $Q_{\mathrm{s}}$ values that appearing during the $t_{\mathrm{p}}$ were $0.35,0.37$, and $0.35 \mathrm{~kg} / \mathrm{m}^{2}$ for $\alpha$ of 0.2 , 0.5 , and 0.8 , respectively. The calculated average $Q_{s}$ for three cases were approximately $0.278,0.286$, and $0.279 \mathrm{~kg} / \mathrm{m}^{2}$, respectively. In the current study, the $Q_{\mathrm{s}}$ of the nonsinusoidal mode were higher than that of sinusoidal mode, which had $Q_{\mathrm{s}}$ of $0.274 \mathrm{~kg} / \mathrm{m}^{2}$ [25].
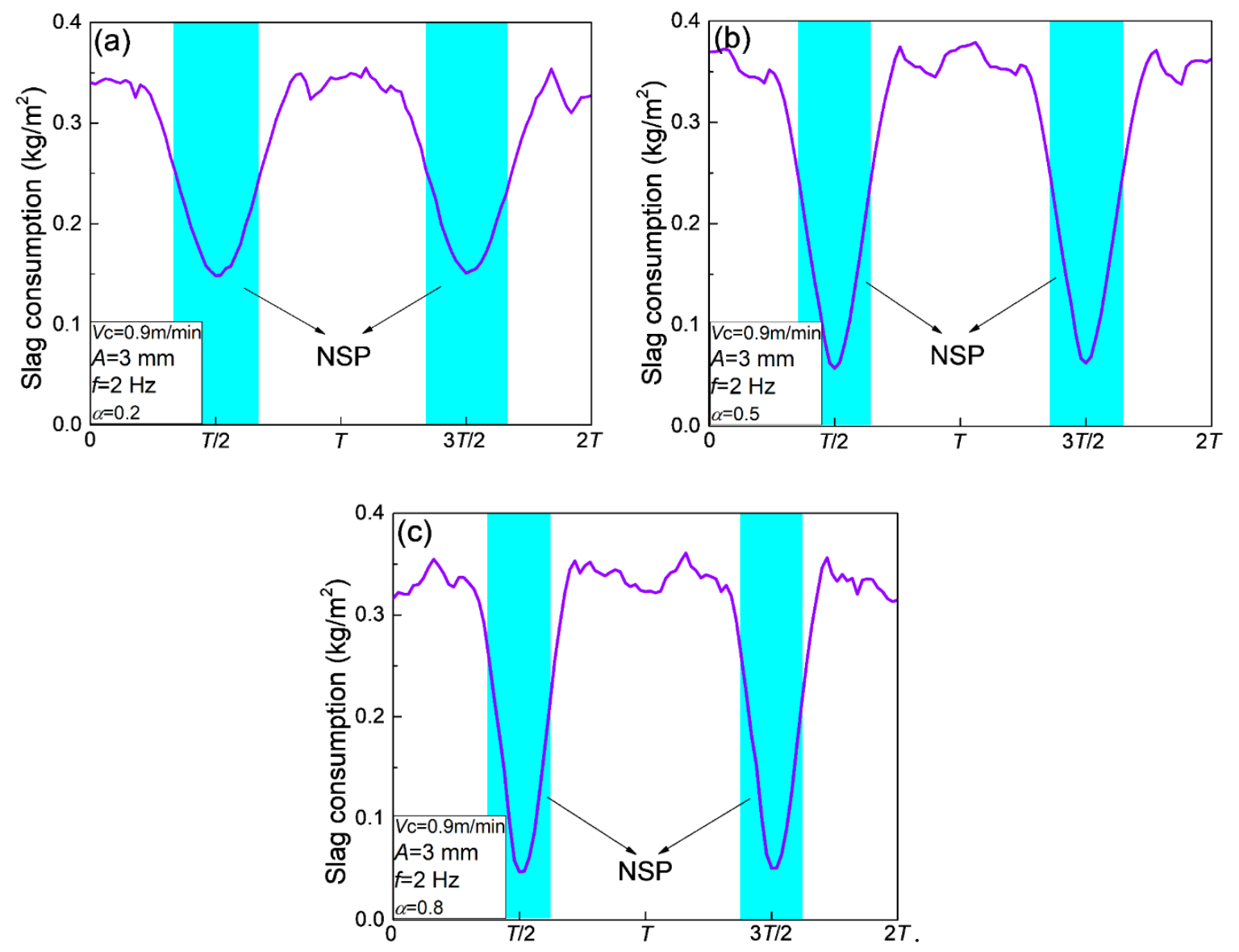

Figure 8. Variations of slag consumption of nonsinusoidal oscillation with different modification ratios: (a) $\alpha=0.2$, (b) $\alpha=0.5$, and (c) $\alpha=0.8$.

Actually, the periodic fluctuation of slag film thickness is closely related to the transient variation of slag consumption during mold oscillation, which also has been reported by Lopez et al. [26]. If the variation of slag film causes violent fluctuation on the local heat flux, some defects, such as cracks, may be generated on the strand surface.

\subsection{Heat Flux and Steel Solidification at Meniscus}

The formation of subsurface hooks is strongly linked to initial shell solidification and growth in the vicinity of the meniscus during continuous casting of steel [27]. The growth of the shell tip with mold oscillation was investigated under conditions of different $\alpha$. The vertical proximity of the shell tip to the root of the meniscus shell was expressed as $d_{\mathrm{m}}$, as indicated in Figure 9a: the case of $\alpha=$ 0 corresponds to sinusoidal mode. A greater $d_{\mathrm{m}}$ signifies a greater separation distance between the shell tip and root of the meniscus, meaning that the initial shell growth is more robust. In Figure $9 b$, nine positions, $P_{1}$ to $P_{9}$, on the mold displacement curve were selected to investigate the variations of transient heat flux at $3 \mathrm{~mm}$ below the initial meniscus and $d_{\mathrm{m}}$ with mold oscillation; $\mathrm{P}_{5}, \mathrm{P}_{6}$, and $\mathrm{P}_{7}$ were located in $t_{\mathrm{n}}$. The predicted results of transient heat flux and $d_{\mathrm{m}}$ are plotted in Figure 10. 

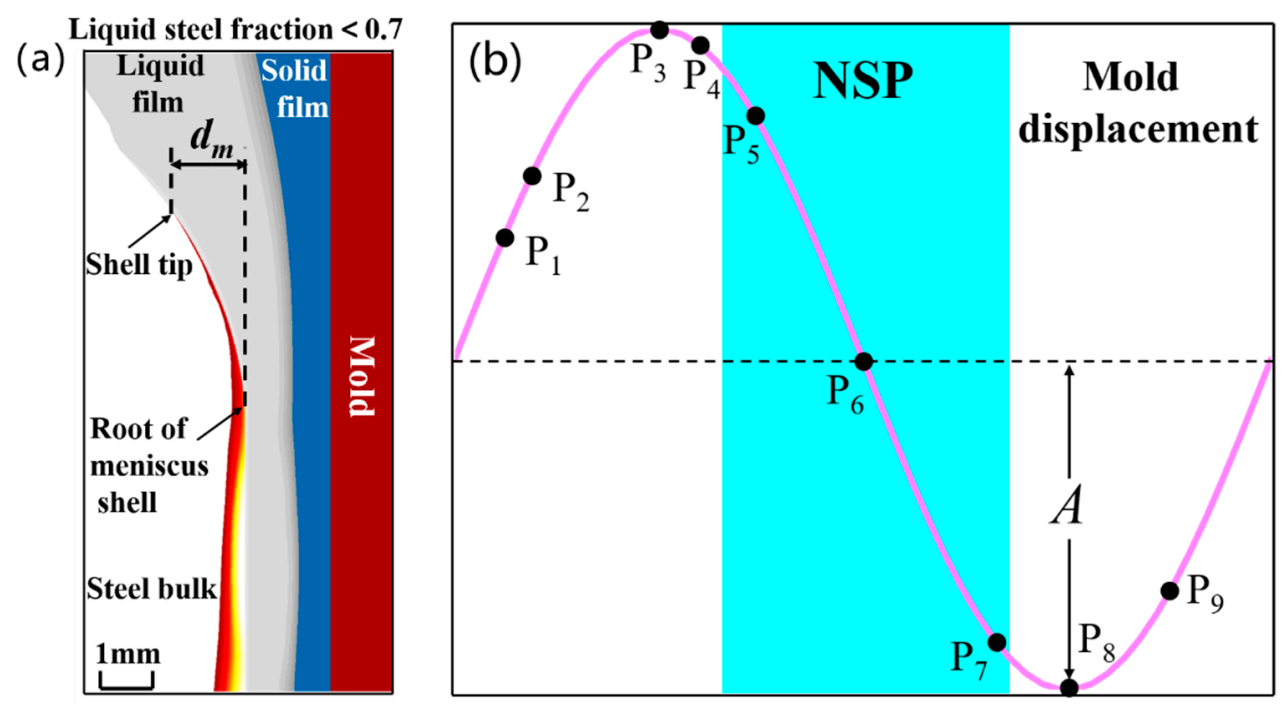

Figure 9. Schematic of (a) solidified shell tip at meniscus and (b) mold displacement.
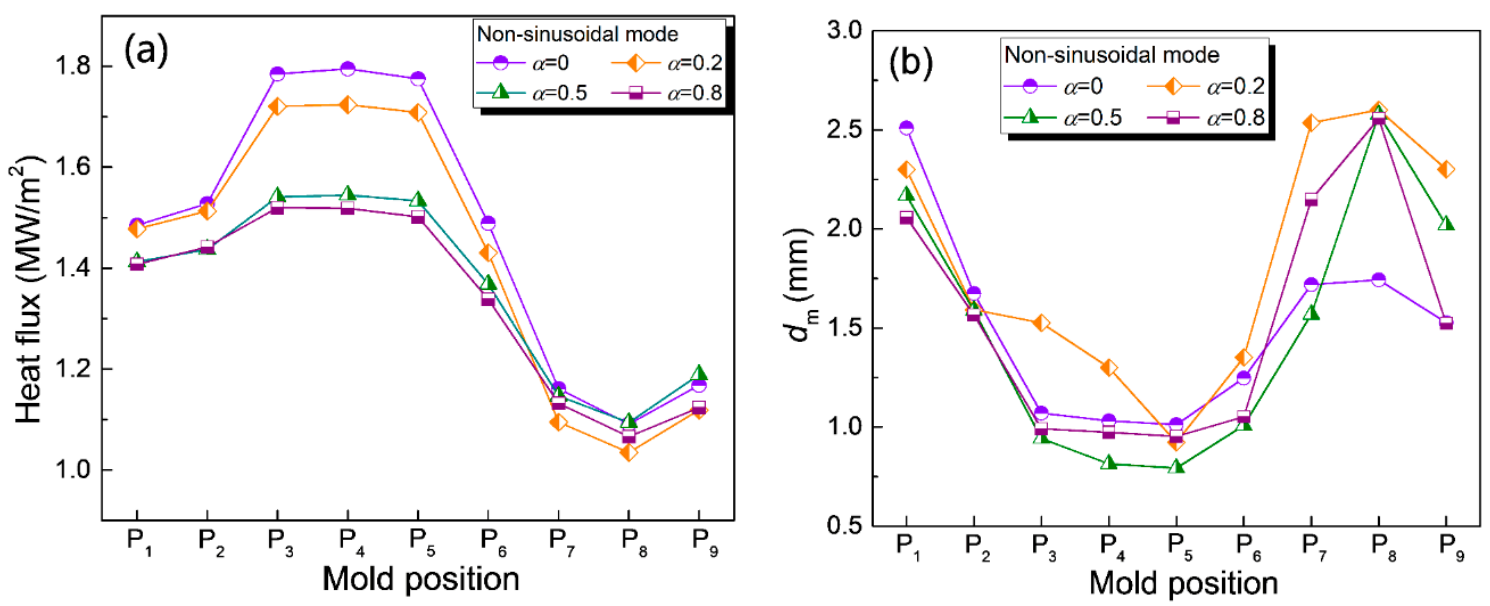

Figure 10. Variations of (a) transient heat flux at $3 \mathrm{~mm}$ below the meniscus. (b) $d_{\mathrm{m}}$ during mold oscillation with different modification ratios.

Figure 10 shows that the changing trend of transient heat flux and $d_{\mathrm{m}}$ were more or less coincident in the four cases of $\alpha$. Moreover, it was found that the heat flux kept an increasing trend, while $d_{\mathrm{m}}$ had a significant reduction when the mold ascended from $\mathrm{P}_{1}$ to the highest position $\mathrm{P}_{3}$; it revealed that there was absence of steel growth during the period. Subsequently, the mold descended from the highest position to $P_{5}$ with a smaller range of motion, there was a slight decrease in heat flux; in the case of $\alpha=0.2, d_{\mathrm{m}}$ obviously decreased, yet only slightly decreased in the other three conditions. The mold continuously oscillated downward from the early part of $t_{\mathrm{n}}$ via the remainder of $t_{\mathrm{n}}\left(\mathrm{P}_{5}\right.$ to $\mathrm{P}_{8}$ ) and the heat flux decreased sharply; while the $d_{\mathrm{m}}$ continuously increased. Especially, $d_{\mathrm{m}}$ was significantly enhanced during the second half of $t_{n}\left(\mathrm{P}_{6}\right.$ to $\left.\mathrm{P}_{7}\right)$, and arrived at the peak value at $\mathrm{P}_{8}$ for the four cases, meaning the meniscus level tends to grow to the molten steel side, then decreased as the mold ascended. It may be speculated that rapid shell growth appeared when the mold was descending, maximum solidification occurred dominantly in the period between the late part of $t_{\mathrm{n}}$ and early part of the next $t_{\mathrm{p}}$, and there was no growth of the shell during the mold ascension, which is consistent with previous studies $[22,26,28]$. Actually, it was generally believed that an increased heat flux was beneficial to the growth of initial solidified shell; but, from the above results, it indicates that the formation of initial shell was not only affected by the heat flux, but also by the infiltration of local liquid slag; the pressure driven by slag rim; and the mold oscillation. 
For the case of $\alpha=0$, the average heat flux and $d_{\mathrm{m}}$ at $3 \mathrm{~mm}$ below the meniscus were $1.48 \mathrm{MW} / \mathrm{m}^{2}$ and $1.5 \mathrm{~mm}$ in a single oscillation cycle, respectively. The obtain results have a good agreement with the reported values by Zhang et al. [29,30], which indicated the accuracy of the established model in the study. In addition, the heat flux fluctuations near the meniscus of nonsinusoidal oscillation were significant smaller than those of sinusoidal oscillation, and the less fluctuations of heat flux is more favorable to the uniform growth of shell. The case with $\alpha$ of 0.5 had a lower value of $d_{\mathrm{m}}$ during the process of the mold descending $\left(\mathrm{P}_{3}\right.$ to $\left.\mathrm{P}_{7}\right)$ and thus its initial shell growth was inferior to that of other cases. Robust growth of the shell tip toward the meniscus is vulnerable to increasing incidences of inclusion and bubble entrapment by the hook [26,27,31]. Consequently, the choice of $\alpha$ can influence the growth of the initial shell at the meniscus: a value of 0.5 is recommended.

It is noteworthy that there is no unified reference standard to choose $\alpha$. The liquid slag infiltration at different moments changes with the variation of $\alpha$, which will cause the slag consumption and pressure in the channel to change, further affects the initial shell solidification and growth near the meniscus. For example, the formation of subsurface hooks is related to the initial shell growth near the meniscus during continuous casting of ultralow carbon steel, the hook is prone to gather large inclusions and pose greater effect to the quality of slabs; thus, the effect of $\alpha$ on the growth of shell tip is mainly focused in this case. In addition, the lubrication is particularly critical in the continuous casting of high carbon steel grades, so it is necessary to pay great attention to the effect of $\alpha$ on slag consumption and liquid slag film. Reference standard varies with the change of steel grades and operation conditions.

\section{Conclusions}

The influence of nonsinusoidal oscillation with different modification ratios on slag infiltration and initial shell growth at the meniscus in slab continuous casting was investigated by employing a two-dimensional multiphase model. The conclusions are outlined as follows.

(1) Liquid slag infiltrates the mouth of the mold-strand channel, mainly accompanied by even distribution of velocity during $t_{\mathrm{p}}$. At the middle of $t_{\mathrm{n}}$, by the action of the copper plate and solid rim, a large amount of liquid slag reflowed into the slag pool. The phenomenon became more severe with an increase of $\alpha$. Simultaneously, the pressure at the lower part of the meniscus increased dramatically.

(2) $\quad \alpha$ had no obvious effect on the average thickness of the liquid film at 100 and $400 \mathrm{~mm}$ below the meniscus, while $\alpha$ of 0.5 had less fluctuation of the transient liquid film.

(3) As $\alpha$ increased from 0.2 to 0.5 to 0.8 , the average slag consumptions were $0.278,0.286$, and $0.279 \mathrm{~kg} / \mathrm{m}^{2}$, respectively. Fluctuation of slag consumption increased as $\alpha$ increased during $t_{\mathrm{n}}$, and the maximum value appearing during $t_{\mathrm{p}}$. Combining with the flow characteristics of the liquid slag, the slag consumption could be increased by appropriately broadening $t_{\mathrm{p}}$.

(4) Shell solidification and growth occurred dominantly in the period that the mold descended and there was little shell growth when the mold was ascending. A $\alpha$ of 0.5 is recommended because the initial shell tip is least robust at the meniscus, which is favorable for preventing the entrapment of inclusions and bubbles and reducing the formation of defects.

Author Contributions: X.Y., Q.W. (Qiangqiang Wang), S.H., and Q.W. (Qian Wang) conceived and designed the numerical simulation; X.Y., and B.J. conducted the simulation and analyzed the simulation results; X.Y. and Q.W. (Qiangqiang Wang) wrote the paper.

Funding: This research was funded by the National Natural Science Foundation of China (Grant Nos. 51804057, U1660204 and 51874057) and the Fundamental Research Funds for the Central Universities in China (Grant No. 2018CDXYCL0018).

Conflicts of Interest: The authors declare no conflict of interest. 


\section{References}

1. Szekeres, E.S. Overview of mold oscillation in continuous casting. Iron Steel Eng. 1996, 73, 29-37. [CrossRef]

2. Shi, Y.M.; Yang, W.G.; Chen, D.L.; Gan, Y. Development of mold oscillation technology for CC. Contin. Cast. 1997, 2, 3-7. [CrossRef]

3. Harada, S.; Tanaka, S.; Misumi, H.; Mizoguchi, S.; Horiguchi, H. A formation mechanismof transverse cracks on CC slab surface. ISIJ Int. 1990, 30, 310-316. [CrossRef]

4. Zang, X.Y.; Wang, X.D.; Ma, Y.; Yao, M.; Zhang, L.; Ye, S.H. The shell surface force caused by mould friction during slab continuous casting. ISIJ Int. 2008, 48, 170-174. [CrossRef]

5. Wang, X.D.; Wang, Z.F.; Yao, M. Online measurement for transient mold friction based on the hydraulic oscillators of continuous-casting mold. Metall. Mater. Trans. B 2013, 44, 1499-1508. [CrossRef]

6. Mizukami, H.; Kawakami, K.; Kitagawa, T.; Suzuki, M.; Uchida, S.; Komatsu, Y. Lubrication phenomena in a mold and optimum mold oscillation mode in high-speed casting. Tetsu-to-Hagane. 1986, 72, 1862-1869. [CrossRef]

7. Suzuki, M.; Miyahara, S.; Kitagawa, T.; Uchida, S.; Mori, T.; Okimoto, K. Effect of mold oscillation curves on heat transfer and lubrication behaviour in mold at high speed continuous casting of steel slabs. Tetsu-to-Hagane. 1992, 78, 113-120. [CrossRef]

8. Shin, H.-J.; Lee, G.-G.; Choi, W.-Y.; Kang, S.-M.; Park, J.-H.; Kim, S.-H.; Thomas, B.G. Effect of mold oscillation on powder consumption and hook formation in ultra low carbon steel slab. In Proceedings of the AISTech 2004, Nashville, TN, USA, 15-17 September 2004.

9. Shin, H.-J.; Kim, S.-H.; Thomas, B.G.; Lee, G.-G.; Park, J.-M.; Sengupta, J. Measurement and prediction of lubrication, powder consumption, and oscillation mark profiles in ultra-low carbon steel slabs. ISIJ Int. 2006, 46, 1635-1644. [CrossRef]

10. Suzuki, M.; Mizukami, M.; Kitagawa, T.; Kawakami, K.; Uchida, S.; Komatsu, Y. Development of a new mold oscillation mode for high-speed continuous casting of steel slabs. ISIJ Int. 1991, 31, 254-261. [CrossRef]

11. Kawakami, K.; Kitagawa, K.; Mizukami, H.; Uchibori, H.; Miyahara, S.; Suzuki, M.; Shiratani, Y. Fundamental study and its application of surface defects of powder cast strands. Tetsu-to-Hagane. 1981, 67, 1190-1199. [CrossRef]

12. Takeuchi, E.; Brimacombe, J.K. The formation of oscillation marks in the continuous casting of steel slabs. Metall. Mater. Trans. B 1984, 15B, 493-509. [CrossRef]

13. Takeuchi, H.; Matsumura, S.; Hidaka, R.; Nagano, Y.; Suzuki, Y. Effects of mould oscillation conditions on oscillation marks of stainless steel casts. Tetsu-to-Hagane. 1983, 69, 248-253. [CrossRef]

14. Tsutsumi, K.; Murakami, H.; Nishioka, S.; Tada, M.; Nakada, M.; Komatsu, M. Estimation of mold powder consumption in continuous casting. Tetsu-to-Hagane. 1998, 84, 617-624. [CrossRef]

15. Wang, H.M.; Li, G.R.; Zhao, Y.T. Dynamic pressure in mould flux channel during mould non-sinusoidal oscillation. Ironmak. Steelmak. 2010, 37, 464-470. [CrossRef]

16. Lopez, P.E.R.; Sjöström, U.; Jonsson, T.; Lee, P.D.; Mills, K.C.; Petäjäjärvi, M.; Pirinen, J. Industrial application of a numerical model to simulate lubrication, mould oscillation, solidification and defect formation during continuous casting. In Proceedings of the International Conference on Modeling of Casting, Welding and Advanced Solidification Processes, Schladming, Austria, 17-22 June 2012.

17. Yang, J.; Meng, X.N.; Zhu, M.Y. Experimental study on mold flux lubrication for continuous casting. Steel Res. Int. 2014, 85, 710-717. [CrossRef]

18. Yang, J.; Meng, X.N.; Zhu, M.Y. Hydrodynamic lubrication during non-sinusoidal oscillation for a continuous casting mould. Mater. Sci. Forum. 2014, 789, 362-369. [CrossRef]

19. Jonayat, A.S.M.; Thomas, B.G. Transient thermo-fluid model of meniscus behavior and slag consumption in steel continuous casting. Metall. Mater. Trans. B 2014, 45, 1842-1864. [CrossRef]

20. Zhang, S.D.; Wang, Q.Q.; He, S.P.; Wang, Q. Study of mechanism of liquid slag infiltration for lubrication in slab continuous casting. Metall. Mater. Trans. B 2017, 49, 2038-2049. [CrossRef]

21. Wu, T.; He, S.P.; Zhu, L.L.; Wang, Q. Study on reaction performances and applications of mold flux for high-aluminum steel. Mater. Trans. 2016, 57, 58-63. [CrossRef]

22. Mills, K.C.; Däcker, C.-Å. The Casting Powders Book; Spinger Nature: Cham, Switzerland, 2017; pp. 19-58, ISBN 978-3-319-53616-3. 
23. Okazawa, K.; Kajitani, T.; Yamada, W.; Yamamura, H. Infiltration phenomena of molten powder in continuous casting derived from analysis using reynolds equation part 1: steady analysis. ISIJ Int. 2006, 46, 226-233. [CrossRef]

24. Macías, A.E.; Castillejos, E.A.H.; Acosta, G.F.A.; Herrera, M.G.; Neumann, F. Modelling molten flux layer thickness profiles in compact strip process moulds for continuous thin slab casting. Ironmak. Steelmak. 2002, 29, 347-358. [CrossRef]

25. Deng, Y.K.; Zhang, Y.B.; Wang, Q.Q.; Wang, Q. Study of mold oscillation parameters and modes on slag lubrication in slab continuous casting. JOM 2018, 70, 2909-2916. [CrossRef]

26. Lopez, P.E.R.; Mills, K.C.; Lee, P.D. A unified mechanism for the formation of oscillation marks. Metall. Mater. Trans. B 2012, 43B, 109-122. [CrossRef]

27. Sengupta, J.; Thomas, B.J.; Shin, H.-J.; Lee, G.-G.; Kim, S.-H. A new mechanism of hook formation during continuous casting of ultra-low-carbon steel slabs. Metall. Mater. Trans. A 2006, 37A, 1597-1611. [CrossRef]

28. Lopez, P.E.R.; Lee, P.D.; Mills, K.C. Explicit modelling of slag infiltration and shell formation during mould oscillation in continuous casting. ISIJ Int. 2010, 50, 425-434. [CrossRef]

29. Zhang, X.B.; Ren, Y.; Zhang, L.F.; Yang, W. Entrapment of inclusions by solidified hooks at the subsurface of ultra-low-carbon steel slab. Metall. Mater. Trans. B 2018, 49, 3186-3199. [CrossRef]

30. Zhang, X.B.; Wang, Q.Q.; Yang, W.; Wang, S.D.; Zhang, L.F. Three-dimensional distribution of hooks in Al-killed low-carbon continuous casting steel slabs. Metall. Mater. Trans. B 2018, 49B, 2533-2549. [CrossRef]

31. Yamamura, H.; Mizukami, Y.; Misawa, K. Formation of a solidified hook-like structure at the subsurface in ultra low carbon steel. ISIJ Int. 1996, 36, S223-S226. [CrossRef]

(C) 2019 by the authors. Licensee MDPI, Basel, Switzerland. This article is an open access article distributed under the terms and conditions of the Creative Commons Attribution (CC BY) license (http:/ / creativecommons.org/licenses/by/4.0/). 